\title{
AUTORIDADE NA ESCOLA E A INSUSTENTÁVEL LEVEZA DO SER
}

\author{
Authority in school and inbearable \\ lightness of being
}

\section{Candido Alberto Gomes ${ }^{[a]}$, Adriana Lira ${ }^{[b]}$, Marlene Monteiro Pereira ${ }^{[c]}$}

[a]Titular da Cátedra Unesco de Juventude, Educação e Sociedade da Universidade Católica de Brasília (UCB), Brasília, DF - Brasil, e-mail: clgomes@ terra.com.br

[b]Mestranda em Educação da Universidade Católica de Brasília (UCB), Brasília, D F - Brasil, e-mail: adrianalira@ucb.br

[c]Mestre em Educação, professora da Universidade Católica de Brasília (UCB), Brasília, DF - Brasil, e-mail: amarleneucb@ hotmail.com

\section{Resumo}

O aumento das violências das/ nas escolas, bem como a crise de autoridade, tem motivado o desenvolvimento de pesquisas, inclusive as que as relacionam com a formação inicial e continuada de professores. Parte destas analisa a socialização profissional do magistério e encontra questões, como novas faces do "choque de realidade" dos docentes. Assim, efetuou-se uma investigação sobre as percepções dos licenciandos a respeito das violências, da autoridade e do seu próprio preparo para fazer face aos problemas emergentes. Os resultados, obtidos por meio de grupos focais realizados com estudantes de magistério, confirmam a sensação de

Rev. Diálogo Educ., Curitiba, v. 9, n. 28, p. 481-496, set./ dez. 2009 
despreparo para a imersão, ainda que gradual, na prática. Um dos temas silenciados na formação e na pesquisa é a autoridade do educador, como esta se define e se mantém. Parece ser um assunto tabu, de que se fala indiretamente, por meio do "controle de classe" e da indisciplina. Esta lacuna pode conduzir ao trato inadequado da realidade e à redução do ímpeto renovador dos novos mestres. Entre as propostas dos participantes, destacam-se a construção de um gradiente teoria-prática mais adequado, o caráter mais aplicado das disciplinas e o desenvolvimento da capacidade de encontrar soluções, sem receituários.

Palavras-chave: Formação de professores. Violências na escola. Autoridade. Sociologia da educação.

\section{Abstract}

The increase of violence of/in schools, as well as the authority crisis, have inspired research projects, including on pre-service and in-service teacher education. Part of them relate these issues to the teacher socialization, finding questions as the reality shock of the new professionals in their professional life. As a result, this project focused on the perceptions of students on their undergraduate programs and their training practices violence in schools. The data were collected by focus groups. Results confirmed their feeling of unpreparedness for gradual immersion in practice. One of the foregone issues was that of the educator's authority. It seems a taboo, indirectly referred when discussing on "class control" and indiscipline. This gap may lead the participants to deal inadequately with reality, so reducing their impetus of renewal. Their proposals pointed out the construction of better theories - practice gradient along the program, disciplines more applied to practice, as well as the development of abilities to find solutions, instead of receiving a sort of cookbook.

Keywords: Teacher education. Violences in school. Authority. Sociology of education.

Rev. Diálogo Educ., Curitiba, v. 9, n. 28, p. 481-496, set./ dez. 2009 


\section{INTRODUÇÃO}

Por que a autoridade na escola tem umainsustentável leveza para grupos de jovens licenciandos, florescentes, plenos de idealismo e desejo de mudar a escola? Sem ambições filosóficas, vale lembrar o famoso romance de Kundera (1983), cujo cenário é o anseio de liberdade e mudança da "Primavera de Praga", logo abortado pelos tanques soviéticos em 1968, há quatro decênios. Leveza e peso são contrastes vividos pelos jovens estudantes: eles não estão engajados no status quo do sistema educacional. Recém-chegados a um novo "território", veem as injustiças que os olhos dos outros, pelo hábito e cansaço, não veem. Porém, o seu caminho é a formatura e 0 ingresso no magistério, isto é, 0 comprometimento com uma nova situação, âncora pesada que envolve processos árduos de adaptação. Comprometimento que, apesar disso, dará sentido à vida profissional para a qual se preparou durante anos. Nesse rápido transitar entre a leveza e o peso, entre ser estudante e ser profissional, abre-se uma fresta de possível renovação, que, como a "Primavera de Praga", pode acabar com o enquadramento forçado e a anestesia talvez eterna do sentimento de injustiça. Em vez de Tomás e Teresa, dois personagens, os jovens são pessoas únicas com duplos papéis, de estudante e de profissional, que se sucedem rapidamente no tempo, como o ar primaveril retornará só em outra primavera, se retornar.

A autoridade do professor encerra o drama da insustentável leveza do ser, quando o aluno-mestre se inicia no mundo da prática profissional e, como aluno, se coloca no lugar de outros alunos, critica0 e até ousa transformá-lo. Todavia, o desfecho pode ser dramático ou trágico, caso, sem o conhecimento da realidade, o jovem agir com impetuosidade e falta de cautela, levando a efeitos contrários aos inicialmente almejados, isto é, o conservantismo educacional. Nesse sentido, a própria noção de autoridade do professor se caracteriza por insustentável leveza numa situação cotidiana de crise. E não só a do professor, mas dos pais e de diversas instituições, entre elas a família e a escola. Há várias décadas se discutem e se enfatizam os efeitos negativos e a ilegitimidade do autoritarismo, bem como os caminhos para a autoridade democrática, não raro tropeçando na produção e obediência às normas, na questão dos limites (e da sua falta) e no participacionismo. Q ue a escola pratica violências, hoje mais simbólicas que físicas, dependendo do sistema educacional, parece um ponto em grande parte consensual (BO URD IE U; PA SSE RO N, 1970; CO RRE IA; MATO S, 2003). Q ue a autoridade é inerente ao papel do professor e que

Rev. Diálogo Educ., Curitiba, v. 9, n. 28, p. 481-496, set./ dez. 2009 
essa autoridade tem sofrido modificações no tempo e no espaço são pontos também amplamente debatidos (DUBET; MARTUCCELLI, 1996; G O ME S, 2005; RENAUT , 2005). Entre as alternativas encontrase um leque tão amplo que vai das formas de democracia às tentativas de recuperação dessa autoridade, numa abordagem como a do back to basics. Igualmente, que a autoridade e as violências são temas hoje necessários à formação de professores, seja na compreensão teórica como nas práticas, também é uma área de convergência. Se o docente é uma liderança estratégica da escola, o decisor na sala de aula, é importante que esteja capacitado a agir, não com receituários e recursos aprendidos por ensaio e erro, mas com a compreensão científica dos fatos, de modo a intervir e efetivamente liderar o processo educativo. Mas estarão esses temas contemplados pela formação do magistério, quer nas teorias, quer nas práticas? O u serão apenas parte implícita, subjacente ou tabu de um currículo informal e oculto, em que as próprias relações entre os professores e seus alunos, os futuros professores seriam alvo de um pacto de silêncio?

E ssasindagações contribuíram em parte para nortearumapesquisa com o objetivo de identificar as necessidades manifestas por licenciandos daUniversidadeCatólica de Brasília sobreasuaformação inicial, em facedas violências nas escolas. Assim, o trabalho se propôs a ouvir e fomentar os debates sobre a formação inicial, quando os participantes realizavam estágio, tendo ou não experiência prévia de magistério. Com isso, a Universidade também se autoavalia. Os resultados devem obedecer à generalização naturalística. Estes têm uma parte imanente à realidade da Instituição, pelas suas peculiaridades e pelas do seu contexto social imediato. Por outro lado, uma parte transcende à sua realidade, na medida em que a Universidadeseguelegislação enormas obrigatórias paratodas as instituições de educação superior para formar educadores.

\section{Panela de pressão \& autoridade}

A literatura dedica importantes reflexões e pesquisas a respeito do papel do professor em face das violências escolares, tanto no Brasil como em outros países. Além das mudanças da sociedade inclusiva, a escola se transformou numa instituição de massa, compulsória pelo menos até certo nível. Não importa se o discente ou a família desejam a matrícula, pois esta é obrigatória, não só em face da lei, mas também da necessidade social de todos se escolarizarem até mais tarde, para não

Rev. Diálogo Educ., Curitiba, v. 9, n. 28, p. 481-496, set./ dez. 2009 
serem excluídos ou não agravarem a sua exclusão social. Portanto, esses fenômenos resultaram da perturbação de acordos entre os diferentes níveis do sistema educacional e os públicos que lhes eram socialmente destinados (BARRERE; SEMBEL, 2002).

Uma das grandes questõesé que não se consegue realizaro processo educativo e a aprendizagem sem um mínimo de ordem na sala de aula e no estabelecimento educacional. Tal ordem, imposta pela escola tradicional, relativamente homogênea, tornou-se hoje cada vez menos efetiva em face de mudanças profundas, definidas de modo diferente por diversos autores, como a crise da legitimidade social (o hiato entre as crenças nos valores e a realidade, assim como a contestação dos valores mais profundos), conforme Habermas (1998); a substituição dos valores originais de sustentação do capitalismo por outros, que os contradizem, segundo Bell (1973); a vida na sociedade de risco, que se equilibra numa cordabamba, embalada pela rapidez e incerteza das mudanças, de acordo com Beck (1992); a compressão do tempo e do espaço que resulta na modernidade líquida, segundo Bauman (2007), além de tantas outras perspectivas. Para Dubet (2003) e Dubet e Martuccelli (1996), o protagonismo juvenil cresceu, sobretudo a partir do pósguerra, contribuindo para que culturas adolescentes e juvenis se fortaleçam em oposição à cultura escolar e aos variados tipos de arranjos familiares. Nestas novas circunstâncias, a socialização deixou de ser vistacomo processo em que uma geração transmite à outra a herança sociocultural, como o atleta que passa a tocha olímpica adiante. A socialização se tornou a construção da experiência individual (subjetivação) dos alunos, interagindo tanto com a cultura escolar quanto com as culturas adolescentes/ jovens. Nestas novas situações, os alunos socialmente aquinhoados, menos distantes da cultura da escola, são capazes de integrar-se às culturas juvenis com limitados desafios àordem escolar. Em contraste, os alunos menos privilegiados emais afastados da cultura escolar enfrentam problemas de fracasso e de falta de sentido dos currículos, os quais os levam ao conflito aberto com a ordem da escola.

Para Renaut (2005), a modernização das relações entre indivíduos, que as fez aparecer como relações de igual para igual, levaram a um efeito dominó, em que desabaram sucessivamente as barreiras do estamento, do gênero e da idade. Como então conceber e praticar a relação educativa no seio de uma cultura em que o outro, como um outro eu, éum igual? Com a autonomização da infância (e, acrescentese, da adolescência), estes grupos se libertaram da autoridade dos adultos e ficam entregues a si próprios e à tirania do seu próprio número. Eis o que Coleman (1963) já constatara na pesquisa sobre as sociedades adolescentes e 0 desenvolvimento dos seus valores e hierarquias,

Rev. Diálogo Educ., Curitiba, v. 9, n. 28, p. 481-496, set./ dez. 2009 
inclusive em oposição aos da escola, ao distribuir recompensas com base na conformação do comportamento a certos padrões (estaria aí uma das raízes do assédio moral entre colegas ou bullying?). A ssinalam-se como exemplos a ridicularização do "nerd" e a valorização do consumo, da beleza física e das capacidades atléticas.

Em tais condições de crise, em que "o que advirá ainda não está decidido" (RENAUT, 2005, p. 116), falta clareza ao que seriam a escola e a família democráticas, fundadas na igualdade e na liberdade. Em meio a esses contornos difusos do porvir e às consequentes incertezas dos comportamentos, 0 autor destaca que a força da tradição foi substituída pelo poder dos especialistas, baseados na competência técnica, que definem e legitimam a transmissão do conhecimento. Uma alternativa ao retorno a um passado indesejável seria a imposição de limites aos direitos-liberdades pelos direitos-proteções indispensáveis às crianças e adolescentes. Num exemplo prosaico, 0 adulto educador tem o dever de impedir que uma criança brinque com fogo em face do direito-proteção que lhe cabe.

Weber (2004) distingue entre 0 poder e a autoridade. 0 primeiro é a probabilidade de alguém impor a própria vontade numa relação social, mesmo contra resistências. A autoridade e a dominação são a probabilidade de encontrar obediência para ordens específicas (ou todas) dentro de um grupo de pessoas. Essa probabilidade se fundamenta numa forma de legitimidade, que pode ser predominantemente tradicional, burocrática ou carismática. A família ea escola se assentavam numa autoridade tradicional que ruiu com a modernidade. Para D ubet (2003), o professor depende cada vez mais do seu próprio carisma, pois, à falta de princípios centrais e homogêneos, os educadores necessitam proceder a arranjos locais entre normas contraditórias e negociar a disciplina em função dos indivíduos, grupos e casos. Renaut (2005) disso discorda: essa pretensa solução de remeter-se ao talento carismático do professor conduz à injusta culpabilização dos educadores que não 0 têm. Mais ainda, trata-se do regresso a uma das formas mais antigas de autoridade, que forneceu a Espinosa uma das suas fórmulas mais importantes: "O s piores tiranos são aqueles que sabem fazer-se amar".

Com efeito, para Costa (1996), é preciso separar dois tipos de poder que, não sendo sinônimos, assumem importâncias diversificadas no contexto organizacional escolar: o poder de autoridade e o poder de influência. A autoridade corresponde ao poder formal, cuja fonte se situa na estrutura hierárquica da organização; já a influência consiste no poder informal que, não estando dependente de processos de legitimação legal, pode ser suportado por diversificadas fontes, tais como o carisma,

Rev. Diálogo Educ., Curitiba, v. 9, n. 28, p. 481-496, set./ dez. 2009 
o conhecimento, a experiência pessoal ou o controle dos recursos. Para ele, o professor detém diversas formas de poder das quais poderá fazer uso, nomeadamente nas situações de conflito e/ ou tomada de decisões. Assim, a autoridade não é uma relação que é escolhida ou evitada, mas uma relação necessária para o convívio social no espaço escolar.

No fogo da crise, a "falta de autoridade" do professor leva-0 a recorrer a formas ineficazes e preocupantes para resolver os problemas da indisciplina, buscando muitas vezes controlar o grupo pormeio de estratégias autoritárias, pautadas em sanções a cargo do seu arbítrio, regressando, assim, a padrões anteriores à modernidade, num ambiente em que as normas são continuamente questionadas. 0 resultado é contraproducente, levando a fragilizar ainda mais a relação entre professor e aluno, quando 0 docente não raro aparece como autor da violência, especialmente simbólica, por meio de atitudes que a ateiam ainda mais. Com isso, se difunde a ideia de que a solução deve vir de fora, de alguém que deve resolver o problema: a direção, o psicopedagogo, os pais, a Secretaria de Educação.

\section{0 professor e o "choque de realidade"}

Clássicos como Lortie (2002) apontam especificidades do magistério e da socialização do professor na formação inicial e no trabalho. As ocupações modelam de certo modo as pessoas e desenvolvem uma cultura própria, como a de médico, advogado, engenheiro etc. Entretanto, a preparação do magistério, como se conhece, é recente e tem conexões débeis com as correntes do desenvolvimento intelectual nas sociedades modernas. 0 que os estudantes aprendem é em grande parte intuitivo e imitativo, em vez de explícito e analítico. Como uma arte, tendem a aprendê-la na prática, isoladamente, confinados às salas de aula, cujas portas, uma vez fechadas, reduzem a visibilidade do professor e a comunicação com os colegas. Mais do que isso, ao contrário de um cirurgião, uma vez formados, passam abruptamente à plena responsabilidade pelas salas de aula: ou nadam ou afundam. Mais ainda, o início da carreira se caracteriza pelo "choque de realidade", velho conhecido da literatura, e pela provação vivida em relativo isolamento, que contribui para o conservantismo. Não é surpreendente que os formados considerem as licenciaturas como muito teóricas, compostas de cursos repetitivos e maçantes, tendo conteúdo intelectual ralo. Declaram que elas apresentam expectativas transcendentais nos estudantes sem prover-lhes os meios

Rev. Diálogo Educ., Curitiba, v. 9, n. 28, p. 481-496, set./ dez. 2009 
para alcançá-las. Falta, portanto, uma base teórico-prática adequada, ao contrário devárias profissões (LO RTIE , 2002). 0 hiato entre a profissão como se imagina e o que ela realmente é conduziu a mudanças na formação inicial do magistério. D entre as diversas experiências, uma pesquisa comparativa assinalou que, na Inglaterra, os alunos-mestres se formam numa espécie de curso sanduíche, utilizando 80\% do seu tempo em escolas, em experiências variadas, com 0 apoio dos melhores professores, e o restante na universidade. É bem verdade que Young (1999) frisou, entre outras limitações, a falta de visão ampla do currículo e da suaintegração, bem como a perspectiva de aprendizagem decomposta no desenvolvimento de habilidades específicas. Em contraste, a França tem uma formação centrada nas instituições de educação superior, que, apesar dos obstáculos, têm introduzido oficinas edramatizações, inclusive sobre as violências nas escolas. $\mathrm{Na}$ Inglaterra, as escolas tendem a constituir equipes mais estáveis de educadores, com apoio dos colegas e supervisores aos iniciantes. Já na França, o isolamento da sala de aula e a solidão dos novos docentes são significativamente maiores (BLAYA, 2003), o que leva a uma intensa autossocialização no primeiro ano de trabalho (DURUT-BELLAT; VAN ZANTEN, 2006).

No que se refere em particular às violências nas escolas, 0 professor se sente despreparado, agravando as suas tensões e arruinando a sua saúde. Quer pelo tempo de carreira, quer pelas lacunas da sua formação inicial, quando se trata de programas para superar as violências nas escolas, o grupo docente torna-se alvo preferencial de ações de formação continuada. Assim, é relatado em experiências da Espanha (ORTEGA; REY, 2002), da Bélgica (BLO MART, 2002), da Grécia (ARTINOPOLOU, 2002) e de outros países. Tendo como foco cada estabelecimento ou vários, eles procuram formar equipes escolares integradas, cujos membros não ajam isoladamente. Com frequência, tais programas, entre outros objetivos, buscam melhorar o relacionamento professor-aluno, estabelecer uma disciplina justa e coerente, aprender a administrar conflitos e criar um clima favorável ao processo educativo, à aprendizagem e, portanto, ao sucesso escolar, com a minimização dos desgastes de todos os grupos integrantes do que precisa constituir-se numa comunidade educativa. Entretanto, existe um abismo entre o que a pesquisa sobre violências nas escolas e comportamentos agressivos oferece e o que chega aos professores por meio da formação inicial e continuada. Royer (2003) confessa a sua perplexidade ante 0 distanciamento pesquisa-prática, como se ainda estivéssemos no tempo da condenação de Galileu. Em contraste com a reatividade ante as

Rev. Diálogo Educ., Curitiba, v. 9, n. 28, p. 481-496, set./ dez. 2009 
violências, as medidas punitivas e o arsenal tecnológico para vigiar e punir, a literatura indica que os métodos exemplares para prevenir violências são baseados num conjunto de valores compartilhados pelos educadores da escola e pelos pais. Por isso, as intervenções precisam de um modelo de referência capaz de explicar, predizer e compreender as violências, modelo este que se estende além da escola, envolvendo a comunidade e serviços para a juventude.

\section{METODOLOGIA}

Nesta primeira etapa da pesquisa, a coleta de dados se fez por meio de seis grupos focais formados por licenciandos dos dois últimos períodos letivos da Universidade, compostos de 10 a 12 participantes, a maioria deles com experiência docente, conforme um roteiro prévio de discussão. Foram representados todos os cursos então mantidos, exceto um. As falas foram gravadas, decodificadas e categorizadas. 0 trabalho, acompanhado sistematicamente pelos pesquisadores, foi em grande parte realizado por mestrandos em educação da própria Universidade, como treinamento, depois de se fundamentarem na literatura e participarem ativamente da construção do projeto e do instrumento utilizado.

\section{RESULTADOS}

\section{0 choque de realidade}

O choque de realidade começou no estágio, apesar de haver visitas e trabalhos em escolas já na primeira metade da licenciatura. Falou-se de "susto", de tremer, de "frio na barriga", de "meu D eus, o que estou fazendo aqui?", de não saber como se portariam diante de uma turma, em especial nas escolas de áreas menos favorecidas. Confirma-se que continua a ocorrer o hiato, já mencionado, entre a preparação do professor e a sua prática. Embora a literatura registre o fato há várias décadas, em particular quanto ao ensino normal, em linhas gerais ele permanece nas licenciaturas. O u seja, elevou-se o nível da formação dos professores, mas o problema permaneceu. Tal como em outros tempos, atribuiu-se a falta de preparo à formação inicial. A preparação continuou a dirigir-se para uma escola ideal, no sentido de

Rev. Diálogo Educ., Curitiba, v. 9, n. 28, p. 481-496, set./ dez. 2009 
minimizar os problemas dos alunos e onde todos os recursos funcionassem: A gente épreparado para dar aula numa escola toda bonitinha... cheirosinha... (C..., participante do grupo focal).

0 estribilho repetido pelos participantes da pesquisa foi 0 de que não se encontravam preparados para agir, mas também é muito difícil preparar-se fora da ação. $\mathrm{Na}$ sua ansiedade, não conseguiram perceber que a preparação é continuada.

Uma das descobertas dos estagiários, peixes ainda pouco comprometidos com o lago da escola, foi a perda do sentido da educação por professores, que, indiferentes, se atinham aos conteúdos e à preparação para o "vestibular", o que foi um choque para o idealismo universitário. Estudantesinsistiram na necessidade denovas metodologias que deixassem claros os porquês e para quês de aprender Física, entre outros componentes curriculares, para que os alunos sejam bemsucedidos. E uma oposição ao conteudismo e ao chamado para a mudança da escola, em face do entrecruzamento de culturas na subjetivação do adolescente (D UBET, 2003).

\section{Primeiros contatos com as violências}

Q uase todos os participantes tiveram contato com as violências. Vários deles escolheram propositalmente escolas de periferia e não "escolas modelos", para conhecer a realidade. Alguns casoslogo afloraram, como o de um aluno que tinha tentado jogar uma pedra na cabeça da professora. 0 agente de segurança logo o abordou também com violência, no calor dos acontecimentos, em reação punitiva. 0 licenciando que relatou o fato, com apoio do grupo, criticou como destrutiva a violência em resposta à violência. Várias foram as narrações de gritos do professor com os alunos e, num caso, se descreveu que os professores, com medo de perder 0 emprego, se calavam diante do diretor. Emergiu também a associação entre escolas de ambientes socialmente desprivilegiados e violências. As escolas particulares, quando bem ordenadas e dispondo de atenção erigor com os alunos, foram consideradas relativamente pacíficas, embora se registrassem observações de que também ocorriam violências, porque "o aluno paga a escola", isto é, comporta-se supostamente como consumidor. Entreas duas pontas destearco, situavam-se escolas públicas, mesmo em áreas de baixa renda, onde não havia "problemas", o que foi associado a estabelecimentos "bem estruturados", inclusive no que tangia aos recursos disponíveis. Quanto ao turno, foram feitas menções

Rev. Diálogo Educ., Curitiba, v. 9, n. 28, p. 481-496, set./ dez. 2009 
divergentes, ora considerando os alunos do diurno mais interessados, ora, ao contrário, desinteressados e inquietos. À noite, duas realidades foram diferenciadas: de um lado, os adultos, com necessidade de escolarização, compenetrados do seu papel, e, de outro lado, os jovens envolvidos com o crime e o tráfico, em áreas de gangues.

\section{O silêncio sobre a autoridade}

O s registros não têm referências diretas à autoridade ou ao papel do professor, como se não fizessem parte dos currículos. As alusões são indiretas, so b aforma de preocupação etemor, algumas vezes confirmados, em face do "controle de classe" e da disciplina dos alunos:

Tenho medo de pegar uma turma com adolescentes agressivos de 18 anos, que vão ser mais altos do que eu, entende? (J., participante do grupo focal)

Se eles não respeitam a mãe, vão respeitar a professora? (A., participante do grupo focal).

No entanto, a maior contribuição das licenciaturas foi a visão crítica dos procedimentos da escola e da sala de aula, bem como a observação das incivilidades dos professores. A falta de relevânciados currículos eprogramas da educação básica, o isolamento da escola em relação à comunidade, as condutas comodistas e a gestão antidemocrática foram apontadas como formas de violência, geradoras de violências por parte dos alunos:

A escola éuma ditadura, você encontra um sistema ferrenho, você não encontra professor no intervalo [...], conversando com aluno, ele está trancado na sala dele. [...] N enhum professor demonstra a sua afetividade para os alunos e não ouve. A cho até que faz questão de não conhecer a realidade da escola (S., participante do grupo focal).

Uma professora de artes não conseguia "dar aula” para um aluno que cumpria medida socioeducativa e pediu ao estagiário: Fica om ele, pelo amor de D eus!... O licenciando perguntou se ele gostava de desenhar. Diante da afirmativa, atribuiu-lhe responsabilidades. D epois de dois tempos de aula, ele haviafeito dezenas de desenhos, para espanto damestra: $\mathrm{N}$ ossa, mas eletem técnica! Tendo ouvido o menino, o professorando descobriu que era filho de traficante,

Rev. Diálogo Educ., Curitiba, v. 9, n. 28, p. 481-496, set./ dez. 2009 
assassinado poroutro traficante, que, depois disso, ficou com a "boca" eaviúva, mãe do menino, isto é, o assassino se tornou seu padrasto. Nem a escola, nem o professor conheciam o aluno, embora o estagiário concluísse prudentemente: Mas também é complicado conhecer 53 alunos só numa turma. D ez turmas são 530.

Vários licenciandos com maior concentração na formação pedagógica, como os de Pedagogia, chocaram-se com os fatos e tomaram atitudes positivas, procurando colocar-se no lugar dos alunos, que não raro tinham os pais atuando na criminalidade ou presos. Como resultado, verificaram-se ações como comunicação das regras do futebol, leitura participativa de livros de história e até um banho coletivo de mangueira, em quetodos descobriram que podiam se divertir sem agressões. No dia seguinte, um menino desenhou as cenas e escreveu: E stávamos todos brincando juntos (sic).

As violências simbólicas e, em particular, as violências da escola foram menos evidentes. Os participantes da pesquisa não chegaram às filigranas do capital cultural, mas observaram não só as violências acima, como a omissão dos professores. Uma das observações mais contundentes foi a de uma escola pública onde o recreio era terra de ninguém. A cuados e fatigados, os professores se omitiam numa sala toda gradeada:

A hora de recreio era hora de roubo, de pancadaria [...], era uma coisa horrível... E u não via nenhum professor... Q uando acontecia alguma coisa, 0 aluno ia até a sala dos professores e 0 professor dizia: A gora é minha hora, eu não sou professor agora. (G., participante do grupo focal)

Com visível influência da pedagogia freireana, diversos participantes apostaram na empatia e no diálogo em suas experiências de sala de aula, com resultados animadores. Uma aluna, em referência singular, chegou a declarar que nem sabia se o professor deveria ser autoridade, embora reconhecesse as dificuldades acarretadas pela falta de respeito, conforme os padrões da autoridade tradicional.

Numa escola a orientação para os professores era não discutir com o aluno que cometesse alguma falta e encaminhá-lo à coordenação. Em outros casos foi descrito que, apesar de não haver essa orientação, os professores logo recorriam à direção. Com isso, se debilitavam ante 0 corpo discente. Nesse sentido, pesquisa realizada em uma escola pública e outra particular (FERNANDES, 2006) verificou que era pouco comum o recurso das vítimas de violências aos professores, o que pode sugerir uma autoridade desgastada, talvez pela prática da "vista grossa", resultante da negociação entre docentes e discentes na arena da sala de aula. As pessoas mais procuradas pelas vítimas no estabelecimento

Rev. Diálogo Educ., Curitiba, v. 9, n. 28, p. 481-496, set./ dez. 2009 
público foram o diretor $(35,7 \%)$, pais $(21,4 \%)$ e colegas $(10,7 \%)$. Não buscaram ninguém, $14,2 \%$. No estabelecimento particular, os pais, clientes pagantes, foram os mais procurados $(38,6 \%)$, seguidos pelos colegas $(16,6 \%)$ e pelo diretor $(14,8 \%)$. O utra pesquisa, também no D istrito Federal, constatou que, em caso de violências, os professores recorrem com maior frequência ao diretor (G O MES, 2008).

\section{A formação pedagógica pela voz dos formandos}

O leque de opiniões variou desdeparticipantes que se disseram sem instrumental teórico e prático ao terminaro curso até os que se consideraram fundamentados para a atuação no magistério, sem receitas prontas, pois a realidade éimprevisível. Entre os primeiros concentraram-se os licenciandos de ciências matemáticas, enquanto os pedagogos predominaram na outra ponta. A maioria acusou falta de prática, que os estágios ficavam para o final, as atividades de campo ao longo do curso não eram suficientes e o preparo se tornava demasiadamente teórico, em outras palavras, reações idênticas às dos educadores estudados por Lortie (2002) em outro tempo e contexto social. A falta derelacionamento entre pesquisa e prática foi problema agudo no consenso da maioria. A mesma falta de prática foi responsabilizada pela desatenção às disciplinas de fundamentos da educação, para as quais muitos acordaram tarde para perceber a sua utilidade. Como autocrítica, alunos de ciências matemáticas enfatizaram a "exagerada preocupação com conteúdos, decoração de fórmulas etc." , quando, na realidade, a educação envolve a comunicação entre seres humanos.

Luzes se acenderam quanto a alternativas e novas percepções. Assim, apesar da crítica ao hiato entre teorias e práticas, participantes notaram que as licenciaturas hoje estão mais preocupadas com o complexo diálogo professor-aluno. Por isso, ressaltaram não haver receitas para todas as situações. O u seja, há necessidade de maior prática, mas, ao mesmo tempo, existe o reconhecimento de que a preparação das licenciaturas não pode ser fixa, em face de uma realidade cambiante. Em outras palavras, a prática, para responder à complexidade do real, precisa de flexibilidade e debate.

\section{CONCLUSÕES}

Nem o professorleniente, "bonzinho”, nem o professor autoritário, nem o professoromisso foram valorizados pelos participantes. Efetivamente, ostrêstipos carecem deautoridade. Isso, porém, não foidito, foidepreendido.

Rev. Diálogo Educ., Curitiba, v. 9, n. 28, p. 481-496, set./ dez. 2009 
A autoridade e a dinâmica do funcionamento da escola e da sala de aula foram elementos quase totalmente ausentes das discussões. Invisíveis como o vento, talvez desconhecidos, só apareceram quando se sentiam os seus efeitos na vida escolar, como o movimento deobjetosvoando. No entanto, aautoridade é um elemento coesivo dos grupos sociais, por desfrutar de um caráter de legitimidade. A parentemente débil, mas na verdade dotada de alta resiliência, ela é o cimento transparente que une pessoas e faz atitudes e decisões terem efeitos. Contudo, a legitimidade e, com ela, a autoridade podem desvanecerse facilmente porque repousam numa ordem moral mutável. Uma pessoa com autoridade pode cair, como um ídolo de pés de barro, se decepcionar os seus comandados ou contrariar os padrões prescritos de comportamento. Por exemplo, seum professor "roubar" anamorada do seu aluno adolescente, isto é, não atender às expectativas de comportamento do seu papel de mestre (queseteriatornado também um adolescente), atéaforçafísica eventualmente empregada pelo aluno contra ele poderia ser entendida e até "legitimada". Conforme Metz (1979), a autoridade envolve o direito admitido de o superior ordenar e o dever de o subordinado obedecer. $\mathrm{O}$ u seja, a autoridade não se baseia em fatos objetivos, como armas, força ou riqueza, mas numa opinião coletivainstável. O sprofessores, pela suaidadeepreparo, são ainda de alguma forma investidos da autoridade tradicional weberiana. Pela legislação e normas, os docentes se revestem hoje predominantemente da autoridade burocrática. Ambasseencontram em crise, masaparentementeoslicenciandos não discutiram isso em seus currículos, nem notaram a fragilidade da ordem escolar. Ao contrário, em muitos casos apostaram nas suas capacidades técnicas e qualidades pessoais, isto é, no seu carisma e influência. Como 0 arsenal de punições escolares se desgasta e, por isso, não pode ser usado com ilimitada frequência, o professor e a ordem social na escola dependem de valores em mudança e da legitimidade deles emanada. Vale muito menos a coerção que medidas consistentes, prontamente tomadas contra comportamentos desviantes ealicerçadas nalegitimidade. É como uma ponte pênsil entre montanhas. Confiantes nas propostas pedagógicas renovadoras, participantes da pesquisa exteriorizaram o medo de não manter a ordem ou o "controle de classe", mas não identificaram os processos que sustentam a ordem escolar que eles manifestaram ardente desejo de alterar, inclusive ousando lançar sementes de mudança. Trata-se de elevado risco que pode transformá-los de jovens críticos e salutarmente inconformados em ingênuos aprendizes de feiticeiros. Nesse sentido, os conhecimentos científicos das licenciaturas devem esclarecer melhor esses processos essenciais, para que os futuros novos docentes não resvalem para a desilusão, 0 cinismo e 0 conservantismo, ajustando-se finalmente às rotinas do status quo. Por falta de adequada compreensão científica e de um gradiente melhor construído entre a formação e a prática de sala de aula, capazes de permitir a avaliação realista

Rev. Diálogo Educ., Curitiba, v. 9, n. 28, p. 481-496, set./ dez. 2009 
de condutas, o sal da terra pode tornar-se insosso. Voltando a Kundera, a leveza pode conduzir a um comprometimento tão pesado quanto os tanques de guerra, ao sacudirem as pontes sobre o Rio Moldávia, amedrontando tanto os cisnes quanto as gentes de Praga.

\section{REFERÊNCIAS}

ARTINO POLOU, V. A violência escolar na G récia: panorama das pesquisas e estratégias de ação. In: D EBARBIEUX, E.; BLAYA, C. (O rg.). Violência nas escolas: dez abordagens européias. Brasília: Unesco, 2002. p. 153-174.

BARRÈRE, A.; SEMBEL, N. Sociologie de l'éducation. Paris: Nathan, 2002.

BAUMAN, Z. Modernidade líquida. Rio de Janeiro: Zahar, 2007.

BECK, Ü. Risk society, towards a new modernity. London: Sage, 1992.

BELL, D. The coming of post-industrial society: a venture in social forecasting. New York: Basic, 1973.

BLAYA, C. School violence and the professional socialization of teachers: the lessons of comparatism. J. Educ. Adm., Bradford, v. 41, n. 6, p. 650-668, 2003.

BLOMART, J. Evitando a violência no ambiente das escolas primárias. In: DEBARBIEUX, É.; BLAYA, C. (O rg.). Violência nas escolas: dez abordagens européias. Brasília: Unesco, 2002. p. 35-62.

BO URD IEU, P.; PASSERO N, J-C. La reproduction: éléments pour une théorie du système d'enseignement. Paris: Minuit, 1970.

CO LEMAN, J. S. The adolescent society: the social life of the teenager and its impact on education. New York: The Free Press of Glencoe, 1963.

CORREIA, J. A.; MATOS, M. (O rg.). Violência e violências da e na escola. Porto: Afrontamento; Centro de Investigação e Intervenção Educativas, 2003.

COSTA, J. A. Imagens organizacionais da escola. Porto: Edições Asa, 1996.

DUBET, F. A escola e a exclusão. Cad. Pesqui., São Paulo, n. 119, p. 29-45, 2003.

DUBET, F.; MARTUCCELLI, D. À l'école: sociologie de l'experience scolaire. Paris: Seuil, 1996.

DURU-BELLAT, M.; VAN ZANEN, A. Sociologie de l'école. 3e éd. Paris: Armand Collin, 2006.

Rev. Diálogo Educ., Curitiba, v. 9, n. 28, p. 481-496, set./ dez. 2009 
FERNANDES, K. T. 0 conceito de violência escolar na perspectiva dos alunos. 2006. 154 f. Dissertação (Mestrado em Educação) - UniversidadeCatólica de Brasília, Brasília, 2006.

GOMES, C. A. A educação em novas perspectivas sociológicas. 4. ed. São Paulo: Ed. Pedagógica e Universitária, 2005.

GO MES, C. A. Avaliação do projeto Segurança Escolar. Brasília: Universidade Católica de Brasília: Unesco, 2008.

HABERMAS, J. 0 discurso filosófico da modernidade. Lisboa: D om Quixote, 1998.

KUND ERA, M. A insustentável leveza do ser. Rio de Janeiro: Record, 1983.

LO RTIE, D. C. Schoolteacher: a sociological study. 2nd. ed. Chicago: University of Chicago Press, 2002.

METZ, M. H. Classrooms and corridors: the crisis of authority in desegregated secondary schools. Berkeley: University of California Press, 1979.

ORTEGA, R.; REY, R. del. Estratégias educativas para a prevenção da violência. Brasília: Unesco, 2002.

RENAUT, A. 0 fim da autoridade. Lisboa: Piaget, 2005.

ROYER, É. What Galileo knew: school violence, research, effective practices and teacher tranining. Journal of Educational Administration, Bradford, v. 41, n. 6, p. 640-647, 2003.

WEBER, M. Economia e sociedade: fundamentos da sociologia compreensiva 4. ed. Brasilia: Ed. da UNB; São Paulo: Imprensa O ficial do Estado de São Paulo, 2004.

YOUNG, M. Repensando la formación de profesores para un futuro globalizado. Lecciones derivadas de la experiencia inglesa. In: ÁVALOS, B.; NORDENFLYCHT, M. E. La formación de profesores: perspectiva y experiencias. Santiago do Chile: Santillana del Pacífico, 1999. p. 168-188.

Recebido: 15/ 02/ 2009 Received: 02/ 15/ 2009

Aprovado: $25 / 03 / 2009$ A pproved: 03/ 25/ 2009

Revisado: 16/ 09/ 2009 Reviewed: 09/ 16/ 2009

Rev. Diálogo Educ., Curitiba, v. 9, n. 28, p. 481-496, set./ dez. 2009 